\title{
Assessment of the Impact of State Programs and Policies on the State and Development of the Dairy Industry (By the Example of Novosibirsk Region)
}

\author{
Chernyakov M.K. ${ }^{1, *}$ Chernyakova M.M. ${ }^{2}$ Usacheva O.V. ${ }^{1}$
}

${ }^{1}$ Novosibirsk State Technical University, 630073, Russia

${ }^{2}$ RANEPA Siberian Institute of Management, 630102, Russia

*Corresponding author. Email: mkacadem@mail.ru

\begin{abstract}
During the last years, the stable interest is raised by the issues of assessing the impact of state programs on the development of the separate sectors of national economy. Studies are carried out both by national and foreign scientists. Although, few studies are dedicated to the search and development of a systemic approach for assessment of efficiency of state regulation of some separate sector. The dairy industry makes a considerable contribution to forming the food, and, consequently, the state safety. It is unknown how the scientists, assessing the efficiency of state programs, link their impact with the dairy industry development. The objective of our study is revealing the interconnection between the system of state regulation of the dairy industry and its economic efficiency drawing on the example of Novosibirsk Region based on the innodiversification approach, including the combination of innovation, diversification and synergistic approaches. For building mathematical models of impact of state programs and policies, we used correlation and regression analysis methods. The study results prove the presence of a functional dependence between the parameters forming the content of state programs and policies, and the efficiency of the dairy industry development. The calculations performed also allowed taking into account the interactions between the parameters having no direct linear interconnection. As it is seen, the developed methodology of assessing the impact of state programs on the dairy industry functioning efficiency will allow amending regional policies in the field of the dairy industry amending, and use budget funds of various levels in a rational way. The scientific novelty of this study is in development of the single method for assessing the impact of the system of state regulation on the dairy industry efficiency.
\end{abstract}

Keywords: dairy industry, food security, government programs, policies, correlation and regression analysis,

simulation, innovative diversification approach

\section{INTRODUCTION}

Interest to food safety issues, in the whole, and to the role of state in this process, in particular, has been increasing in the entire world. One of the key food safety directions is the population provision with dairy products [1]. In connection with this, it is required to provide the stable efficient development and sector functioning. The dairy industry, being the inseparable part of food industry, is present in any state, but its condition and the level of development in various countries have huge differences. Dairy industry leaders are such economically developed countries as European countries, the USA, India, China, New Zealand, and Australia. At this, the main milk manufacturer is the USA holding $25 \%$ of the entire production volume [2]. Russia enters the top ten of largest manufacturers and holds the sixth place, with approximately $8 \%$ of milk production in total volume falling on its share.

The dairy industry state and development are considerably influenced by the existing national system of state regulation of this economy sector. In its turn, high requirements are set to the state managing system, one of which is its efficiency. Numerous studies in scientific literature are connected with assessing state programs and policies [2-6]. However, few authors analyze interconnections between state programs and the efficiency of development of sectors for which these programs are formed [4]. In our opinion, studying the state 
policy impact on the dairy industry state and development is of considerable scientific interest. In our study, we would like to generalize the experience accumulated and to offer the uniform approach to the assessment of the impact of the state regulation on the dairy industry establishments functioning efficiency.

The results of our and similar studies will be of interest to specialists dealing with development and implementation of state programs and policies, managers of the dairy industry enterprises, and scientists carrying out research in this and adjacent directions.

\section{LITERATURE REVIEW}

For last decade, the negative milk production dynamics has been observed in Russia. Despite the milk production decrease, dividing the cow population into the milking and meat herd, caused the milk production efficiency increase. According to experts, the all-Russian trend of reducing the cow population in agriculture caused the decrease of raw milk production in the industrial sector by $43,4 \%$. Due to the milking hear reduction, cattle population decreased, causing the negative impact on meat industry.

According to the study by V.A. Sirotkin and Ye.A. Schibanikhin, the interaction of two factors, such as the animal productivity growth and the milking herd decrease, form a trend of the priority rate of cattle number decrease in comparison to milk yield from 1 animal. At tis, it is fairly noted that this trend is typical both for regions, and for the country in the whole [7].

At the same time, reduction in consumption of milk and the dairy products has a negative impact on the health of Russian citizens. Milk and milk products are traditionally classified as essential items because they provide the balanced nutrition. The share of the dairy products in the food basket structure varies in the range of $20-30 \%$, depending on the region. In accordance with the recommendations of the Ministry of Health of Russia, the standard consumption of the dairy products per one person a year is $325 \mathrm{~kg}$. Therefore, during almost ten years, the actual consumption of the dairy products by the Russian population is much lower than the recommended value, equaling $225.2 \mathrm{~kg}$, i.e., less than $70 \%$ from the aforementioned value, in 2018. The main reason of limiting the growth of the dairy products consumption is the decrease of actual available income of the population. In terms of limiting the import, the increase of the agricultural products production, one of the basic elements of which is milk, is a factor contributing to the reaching of threshold values of food safety indicators in Russia. D.A. Loginov specifies the share of agriculture state support in the value of produced agricultural products as one of the efficient food safety indicators [8]. The criterial indicator value will be the average level of this indicator achieved for the previous five years in the USA and the EU - $25.06 \%$ (compared to $14.79 \%$ actually achieved in 2017). In particular, it indicates at the need for such level of the sector state support that would allow national agricultural manufacturers at the global market, at the comparable level of technologies applied, to compete with import food suppliers, and represent their products at the global market, in the conditions of global competition in order to form the competitive agriculture.

Modern policy of the dairy industry state support led to the increase in volumes of raw milk at the simultaneous decrease of the dairy products consumption, which is illustrated on Figures 1,2.

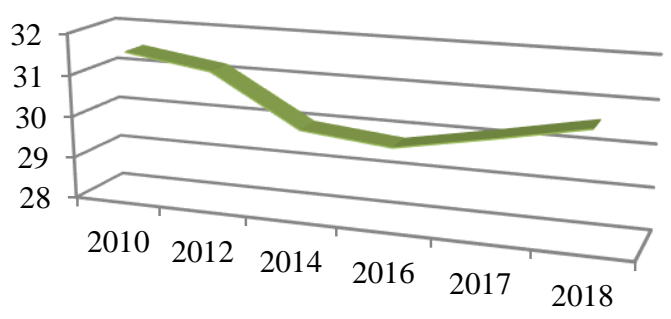

Figure 1 Milk production dynamics for 2010-2018, mln. tons

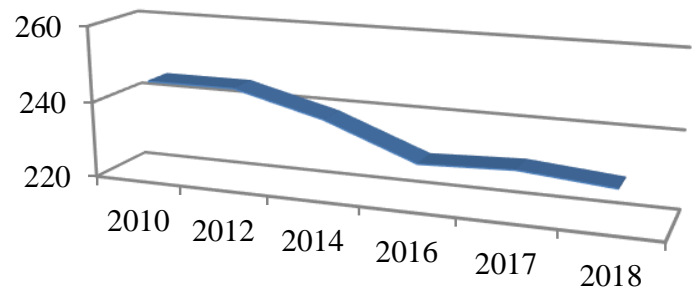

Figure 2 Dynamics of per capita consumption of the dairy products for 2010-2018, kg/prs/year

At this, the dairy industry of Russia has the strong state sponsorship both on the federal and the regional levels. System of national support of agricultural manufacturers includes several directions, namely:

- preferential loans;

- subsidies (compensating and stimulating);

- preferential leasing.

For the time being, the dairy industry, being a part of the agricultural and industry complex, is regulated by various legislative acts and supported by state programs, including the following:

- Concepts of Russian Long-Term Social and Economic Development till 2020;

- Russian National Security Doctrine;

- Strategy of Russian Economical safety till 2030;

- Strategy of Russian food and pharmaceutical processing sectors Development till 2020;

- Federal Law "On agricultural development";

- Program for Development of Agriculture and Regulation of Agricultural Commodity Markets for 2013-2020. 
Each state program as its key parameters - indicators of its implementation efficiency. However, many scientists have doubts about the fact that the indicators set in the programs allow carrying out the full assessment of the program implementation [1-2,8].

For example, in order to provide food safety, one of the main indicators is the level of self-provision with milk and milk products of not less than $90 \%$.

Key indicators of implementing the Program for Development of Agriculture and Regulation of Agricultural Commodity Markets for 2013-2020 are: growth of the index of livestock products production (in comparative prices) by $20.8 \%$, growth of the index of physical volume of investments into the main agricultural stock by $36 \%$, increasing the profitability of agricultural organizations at least by $10-15 \%$ (with regard of subsidies),

According to some authors, not all state subsidies favor the dairy industry development, and it is difficult to determine the interconnection between the specific program and the industry development indicators [2]. Many studies, both national $[2-4,8,9]$, and foreign [10-12], raise the issues of assessing the state impact on the dairy industry. For example, in his paper, Twine E. assesses the impact of the state regulation factors on manufacturers and consumers of the dairy products and substantiates the selection of an optimal option, in his opinion [13]. An opinion is expressed about the public-private partnership necessity in the field of the dairy industry regulation [6]

But, despite the considerable number of studies and publications in this field, some key issues remained partly studied. In particular, economic science did not develop any uniform approach to studying the impact of a state regulation on the efficiency of dairy industry enterprises functioning.

The study conducted is based on the data of one of the largest Russian entities, Novosibirsk Region. The Russian region selction is conditioned by several reasons. First, Novosibirsk Region is included into TOP 10 regions with the largest number of cows in agricultural organizations, peasant (farm) economy and individual entrepreneurship, and is included into TOP 10 Russian regions in terms of milk production and sales. At this, Novosibirsk Region holds the first position in the Siberian Federal District and the second position in the Russian Federation in number of dairy cows. The specific weight in total cow population in Russia as of the end of 2017 was $2.3 \%$. It is twice less if compared to the leading region (Republic of Dagestan). The aggregate share of TOP 10 regions is over $37 \%$, and the share of TOP 20 regions, over $57.5 \%$, which proves the absence of the well-expressed regional concept. Second, in 2017 Novosibirsk Region was the second region in Russia in terms of cow milking efficiency. Therefore, the selected Russian subject is characterized by two the most meaningful characteristics for the study: the expressed cow population specialization (milk direction) and their high productivity.

\section{STUDY METHODS}

\subsection{Inno-diversification approach}

Based on the previous studies results [14], the foundation of further research may be represented by the methodology of the inno-diversification approach, including the combination of innovation, diversification and synergistic approaches. The terms offered give rise to the wording of the inno-diversification approach, as a set of innovation, diversification and synergistic approaches, the combination of which increases their strong sides and compensates the weak sides. Inno-diversification approach provides for the target change in functioning of the organization as the single management object.

With regard of the impossibility to establish the direct linear connection between the most indicators characterizing the dairy industry (Fig. 3), an attempt was made to apply the inno-diversification approach for solving this task.

\subsection{Initial data}

The goal set can be achieved with neural networks [17-18] or Petri networks [19], but such solutions are complex for practical use by the most users in the dairy industry organizations. For this reason, the task was set to simplify the decision-making mechanism for achieving the goal set on the level of office software packages, habitual for users. A hypothesis has been developed [20] that the innodiversification approach will allow taking into account the direct interconnection between the parameters, if possible, and the indirect one, where such interconnection cannot be established. The hypothesis proposed assumes the existence of some multi-level model that could describe the interaction of indicators characterizing the dairy industry with the sufficient degree of accuracy.

In order to confirm the developed hypothesis based on inno-diversification approach, its approbation is suggested to be carried out based on the actual working data of the dairy industry of Novosibirsk Region (Table 1). 
$\mathrm{X} 1$ - milk in farms of all categories

X2 - marketed milk

The number of cows at the end of the year. thousand heads

X3 - in farms of all categories at the end of the year

X4 - in agricultural organizations (agricultural enterprises), peasant farms (peasant farms), personal subsidiary farms (LPH)

\begin{tabular}{|c|c|}
\hline The share of breeding cows, $\%$ & $\begin{array}{l}\text { X5 - in agricultural enterprises, peasant fa } \\
\text { X6 - milk and biased directions of producti }\end{array}$ \\
\hline Milk cow productivity kg / year & $\begin{array}{l}\text { X7 - in farms of all categories } \\
\text { X8 - in the agricultural organization } \\
\text { X9 - in KFK } \\
\text { X10 - in LPH } \\
\text { X11 - breeding cows }\end{array}$ \\
\hline $\begin{array}{l}\text { Milk and dairy products } \\
\text { per capita, kg / year }\end{array}$ & $\begin{array}{l}\mathrm{X} 12 \text { - production } \\
\mathrm{X}-13 \text { - consumption }\end{array}$ \\
\hline Milk processing, tons & $\mathrm{X} 14$ - dairy production in terms of milk \\
\hline Amount of funds, million rubles & X15 - state support for the dairy industry \\
\hline
\end{tabular}

Figure 3 Classification of indicators characterizing the dairy industry [15-16]

Table 1 Non-specific values of indicators characterizing the dairy industry of Novosibirsk Region [13-14]

\begin{tabular}{|c|c|c|c|c|c|}
\hline \multirow{2}{*}{$\begin{array}{c}\text { Designation } \\
\text { of parameters }\end{array}$} & \multicolumn{5}{|c|}{ Period analyzed } \\
\cline { 2 - 6 } & $\mathbf{2 0 1 4}$ & $\mathbf{2 0 1 5}$ & $\mathbf{2 0 1 6}$ & $\mathbf{2 0 1 7}$ & $\mathbf{2 0 1 8}$ \\
\hline X1 & 660,5 & 661,5 & 667,6 & 710 & 729,5 \\
\hline X2 & 477,2 & 485,5 & 495,7 & 549 & 603,6 \\
\hline X3 & 191,8 & 193,8 & 187,7 & 192,7 & 189,4 \\
\hline X4 & 137,2 & 138,9 & 141,1 & 147,4 & 145 \\
\hline X5 & 13,2 & 13,5 & 14,1 & 16,8 & 18,2 \\
\hline X6 & 11,7 & 12 & 12,5 & 15,5 & 16,9 \\
\hline X7 & 3587,0 & 3664,0 & 3724,0 & 4052,0 & 4224,6 \\
\hline X8 & 3903,0 & 4076,0 & 4213,0 & 4534,0 & 4814,0 \\
\hline X9 & 2647,0 & 2753,0 & 2787,0 & 3058,0 & 3208,7 \\
\hline X10 & 2961,0 & 2771,0 & 2767,0 & 2926,0 & 2914,4 \\
\hline X11 & 7327,0 & 7827,0 & 8327,0 & 8943,0 & 8950,0 \\
\hline X12 & 186,9 & 184,4 & 185,9 & 197,2 & 204,2 \\
\hline X13 & 285,0 & 282,0 & 278,0 & 280,0 & 294,2 \\
\hline X14 & 176389,9 & 176341,0 & 158979,6 & 163967,3 & 151724,7 \\
\hline X15 & 480,8 & 573,3 & 699,5 & 1425,3 & 735,8 \\
\hline
\end{tabular}




\section{STUDY RESULTS}

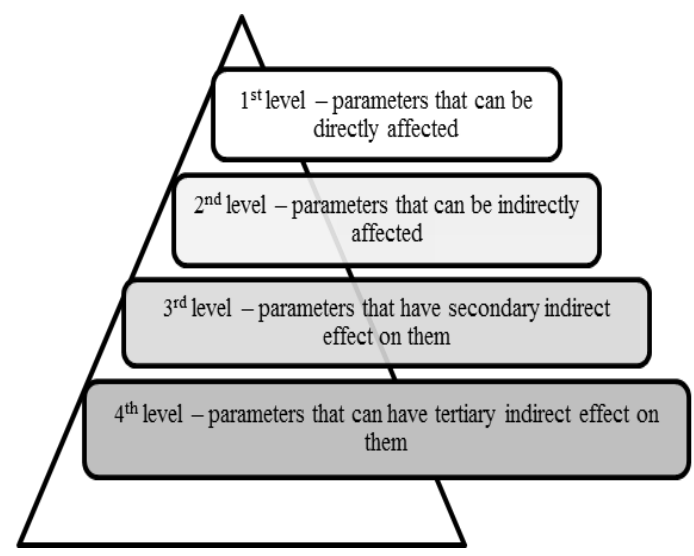

Figure 4 Four-level model of the dairy industry parameters interconnection [21]

Based on the task set, conditions and restrictions imposed at its solution, the existence of a multi-level model of stepwise interactions of the dairy industry indicators and the regulatory interaction factor can be theoretically admitted. The structure of this hypothetical four-level model is given on Figure 4. Number of levels in the model is not strictly regulated and strongly depends on the number of optimization parameters. Number of levels can increase with the increase of the number of parameters, and fall at their reduction. Scenarios can be changed depending on the investigator's objectives and tasks.

The mechanism of implementing the multi-level stepwise interaction model is given on Figure 5.

"Initial data" section (Fig. 5) provides the information about the number of parameters studied $(\mathrm{K})$, analysis time periods $(\mathrm{P})$ and matrix $\mathrm{X}(\mathrm{K}, \mathrm{P})$ of values of each parameter in time intervals (Table 1). "Regulation selection" section states a parameter (one or more), the impact of which on the other parameters is subject to analysis.

When the initial information is entered, the matrix $\mathrm{X}(\mathrm{K}, \mathrm{P})$ correlation analysis is carried out according to the data given in Table 1. Values of the regulator correlation factors are extracted from the correlation matrix (Table 2), and ranked related to the other indicators in decreasing order (Table 3).

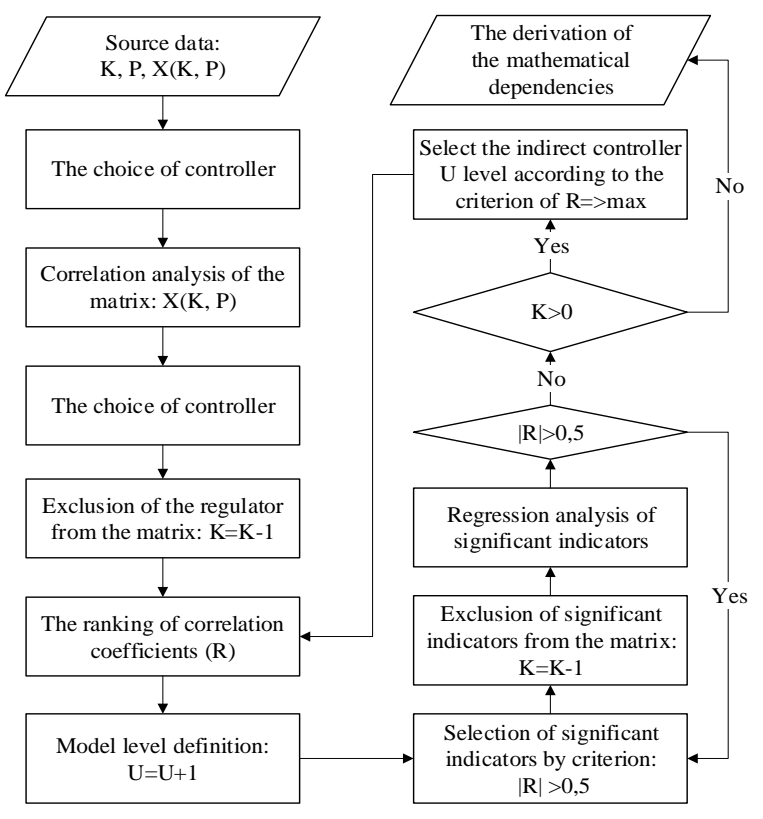

Figure 5 Algorithm of the implementation mechanism for the model of parameter interaction of the dairy industry in the form of a digital technology [20]

Further, the model level is calculated. By default, the level equals zero in the initial state. As the result, we obtain: $U$ $=0+1=1$ for the first level (of direct) impact, $U=1+1=2$ - for the second level (of indirect) impact, etc.

Then, the cycle is introduced for the selection of indicators that are meaningful for this level. They are excluded from the matrix of values, and the regression factors are determined, depending on the regulator (direct, indirect, first level, etc.). The cycle is repeated until an indicator is found with the limitation criteria lower than the set one.

In case $\mathrm{R}<0.5$, the presence of a number of non-analyzed parameters is studied. If $K>0$, the indirect regulator of the Uth level is selected under the criterion of the highest correlation factor from significant indicators of $\mathrm{R}=>\max$ level, the algorithm starts analyzing the next model level, and the process of ranking the correlation factors of the remaining parameters is repeated.

Otherwise $(K=0)$, the mechanism ceases its operation, and the result represented in the form of mathematical dependencies can be used for further analysis, simulation, and forecasting.

Contrary to the conventional approach to the regulation and stimulation of the dairy industry in the region, the inno-diversification approach allows taking into account interactions between parameters having to direct linear interconnection, in continuously changing conditions. Through the mechanism of the digital technology (Fig. 5), created under the concept offered, a possibility will appear to forecast the results from the regulating disturbing impacts (state support, investments, etc.) in real time. 
Table 2 Results of correlation analysis of the main dairy industry indicators for 2014-2018

\begin{tabular}{|c|c|c|c|c|c|c|c|c|c|c|c|c|c|c|c|}
\hline Indicators & $\mathrm{X} 1$ & $\mathrm{X} 2$ & $\mathrm{X} 3$ & $\mathrm{X} 4$ & $\mathrm{X} 5$ & X6 & $\mathrm{X} 7$ & $\mathrm{X} 8$ & X9 & $\mathrm{X} 10$ & X11 & $\mathrm{X} 12$ & $\mathrm{X} 13$ & $\mathrm{X} 14$ & $\mathrm{X} 15$ \\
\hline $\mathrm{X} 1$ & 1,00 & 0,99 & $-0,18$ & 0,88 & 1,00 & 1,00 & 0,99 & 0,97 & 0,99 & 0,45 & 0,88 & 0,99 & 0,60 & $-0,77$ & 0,58 \\
\hline $\mathrm{X} 2$ & 0,99 & 1,00 & $-0,26$ & 0,82 & 0,99 & 0,99 & 0,98 & 0,98 & 0,98 & 0,38 & 0,86 & 0,98 & 0,67 & $-0,81$ & 0,46 \\
\hline $\mathrm{X} 3$ & $-0,18$ & $-0,26$ & 1,00 & $-0,12$ & $-0,22$ & $-0,19$ & $-0,21$ & $-0,30$ & $-0,20$ & 0,18 & $-0,30$ & $-0,18$ & $-0,13$ & 0,74 & 0,17 \\
\hline $\mathrm{X} 4$ & 0,88 & 0,82 & $-0,12$ & 1,00 & 0,89 & 0,89 & 0,90 & 0,89 & 0,90 & 0,26 & 0,96 & 0,81 & 0,15 & $-0,71$ & 0.87 \\
\hline $\mathrm{X} 5$ & 1,00 & 0,99 & $-0,22$ & 0,89 & 1,00 & 1,00 & 0,89 & 0,98 & 0,99 & 0,40 & 0,91 & 0,98 & 0,57 & $-0,80$ & 0,59 \\
\hline X6 & 1,00 & 0,99 & $-0,19$ & 0,89 & 1,00 & 1,00 & 1,00 & 0,98 & 0,99 & 0,41 & 0,90 & 0,98 & 0,57 & $-0,78$ & 0,59 \\
\hline$X 7$ & 0,99 & 0,99 & $-0,21$ & 0,90 & 1,00 & 1,00 & 1,00 & 0,99 & 1,00 & 0,35 & 0,92 & 0,97 & 0.56 & $-0,80$ & 0,59 \\
\hline $\mathrm{X} 8$ & 0,97 & 0,98 & $-0,30$ & 0,89 & 0,98 & 0,98 & 0,99 & 1,00 & 0,99 & 0,23 & 0,94 & 0,93 & 0,53 & $-0,86$ & 0,55 \\
\hline X9 & 0,99 & 0,98 & $-0,20$ & 0,90 & 0,99 & 0,99 & 1,00 & 0,99 & 1,00 & 0.30 & 0,93 & 0,95 & 0,54 & $-0,80$ & 0,58 \\
\hline $\mathrm{X} 10$ & 0,45 & 0,38 & 0,18 & 0,26 & 0,40 & 0,41 & 0,35 & 0,23 & 0.30 & 1,00 & 0.08 & 0,55 & 0,49 & $-0,03$ & 0,26 \\
\hline X11 & 0,88 & 0,86 & $-0,30$ & 0,96 & 0,91 & 0,90 & 0,92 & 0,94 & 0,93 & 0.08 & 1,00 & 0,81 & 0,21 & $-0,84$ & 0.73 \\
\hline $\mathrm{X} 12$ & 0,99 & 0,98 & $-0,18$ & 0,81 & 0,98 & 0,98 & 0,97 & 0,93 & 0,95 & 0,55 & 0,81 & 1,00 & 0,69 & $-0,73$ & 0,50 \\
\hline X13 & 0,60 & 0,67 & $-0,13$ & 0,15 & 0,57 & 0,57 & 0.56 & 0,53 & 0,54 & 0,49 & 0,21 & 0,69 & 1,00 & $-0,39$ & $-0,26$ \\
\hline X14 & $-0,77$ & $-0,81$ & 0,74 & $-0,71$ & $-0,80$ & $-0,78$ & $-0,80$ & $-0,86$ & $-0,80$ & $-0,03$ & $-0,84$ & $-0,73$ & $-0,39$ & 1,00 & $-0,33$ \\
\hline X15 & 0,58 & 0,46 & 0,17 & 0.87 & 0,59 & 0,59 & 0,59 & 0,55 & 0,58 & 0,26 & 0.73 & 0,50 & $-0,26$ & $-0,33$ & 1,00 \\
\hline
\end{tabular}

Table 3 Results of ranking the correlation analysis of the dependence of state support funds volume of the dairy industry and other indicators characterizing the dairy industry

\begin{tabular}{|c|c|c|c|c|c|c|c|c|c|c|c|c|c|c|}
\hline & $\mathrm{X} 4$ & $\mathrm{X} 11$ & $\mathrm{X} 5$ & $\mathrm{X} 6$ & $\mathrm{X} 7$ & $\mathrm{X} 1$ & $\mathrm{X} 9$ & $\mathrm{X} 8$ & $\mathrm{X} 12$ & $\mathrm{X} 2$ & $\mathrm{X} 10$ & $\mathrm{X} 3$ & $\mathrm{X} 13$ & $\mathrm{X} 14$ \\
\hline $\mathrm{X} 15$ & 0.87 & 0.73 & 0,59 & 0,59 & 0,59 & 0,58 & 0,58 & 0,55 & 0,50 & 0,46 & 0,26 & 0,17 & $-0,26$ & $-0,33$ \\
\hline
\end{tabular}

\section{DISCUSSING THE RESULTS}

The mechanism of implementing the multi-level stepwise interaction model is given on Figure 4. "Initial data" section (Fig. 5) provides the information about the number of parameters studied $(\mathrm{K})$, analysis time periods $(\mathrm{P})$ and matrix $X(K, P)$ of values of each parameter in time intervals
(Table 1). "Regulation selection" section assigns a parameter (one or more), the impact of which on the other parameters is subject to analysis.

Using the regression analysis method, it is possible to obtain dependence between the main parameters as a linear function. Algorithm of digital technology for forecasting the results of regulating the parameters of the NSR dairy industry is given on Figure 6. 


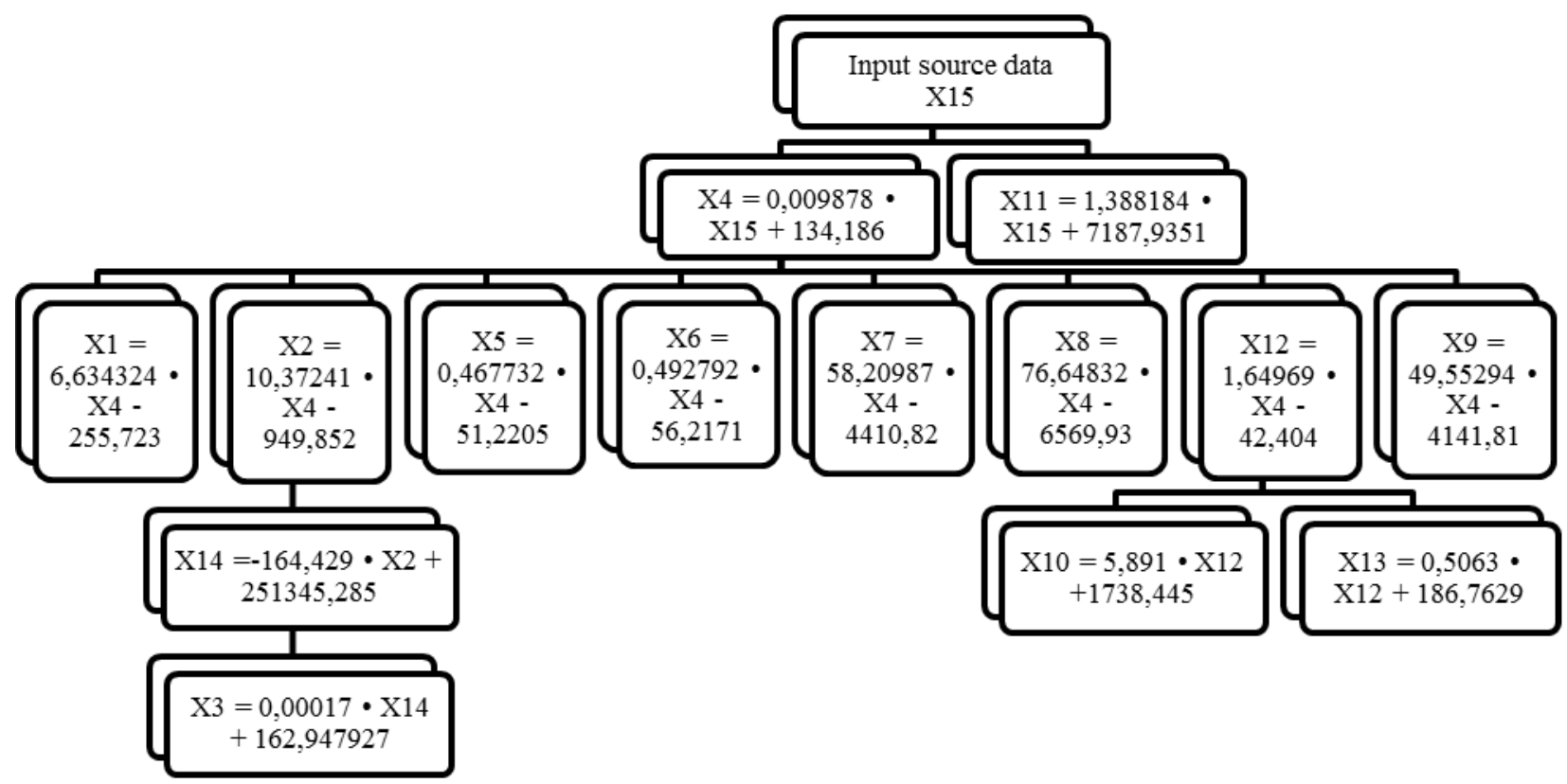

Figure 6 Algorithm of the model of parameter interaction of the dairy industry of Novosibirsk Region

As the result of designing digital model algorithms for regulating the parameters of NSR dairy industry, both common regularities and specific features were established.

The regulators of direct and indirect impact are the similar, and differences occur only on the lower interaction levels. Digital technologies, developed on their basis, allowed forecasting probable values of the industry parameters depending on the regulating impact [19] with the sufficient degree of liability (deviations did not exceed 10\%)

\section{CONCLUSION}

The article has covered the Inno-diversification approach to the assessment of the state impact through the implementation of programs on the dairy industry state and development.

The study results prove the presence of common regularities in direct and indirect impact of state programs on the industry development on the highest level of their interaction. The lower is the interaction level (region, municipality), the more are expressed the specific features of the state impact.

The study contributes to the development of theoretical approaches to the assessment of interactions of the real economy sector and the state. The study practical utility is represented by the possibility of using the offered innodiversification approach through the digital technology mechanism for assessment and forecast of the results of the dairy industry development with regard of the state regulation impact in real time.

\section{ACKNOWLEDGMENT}

The article was prepared under the sponsorship of Novosibirsk State Technical University (project No. 19-12).

\section{REFERENCES}

[1] A.A. Kuzin, N.A. Medvedeva, K.A. Zadumkin, V.V. Vakhrusheva, Development Scenarios for Russia's Dairy Industry, Economic and Social Changes $^{\wedge}$ Facts, Trends, Forecast, 2018, V.11, No.6, pp.73-88.

DOI:

https://doi.org/10.15838/esc.2018.6.60.5

[2] A. Panyshev, O. Katlishin, Efficiency of state regulation and subsiding of the dairy cattle industry in the Russian Federation from the view of indicative planning agricultural industry, AMAZONIA INVESTIGA, 2020, 25, pp.78-87. https://www.amazoniainvestiga.info/index.php/amazoni a/issue/view/25

[3] I.V. Baranova, Target programs of the city of Novosibirsk and problems of evaluating their performance, Finance, 2009, No.3, pp.56-68

https://www.elibrary.ru/item.asp?id=20403680 
Management Review, 2020, pp.55-69. DOI: https://doi.org/10.22434/IFAMR2018.0108

[13] E. Twine, Production and Consumption Responses to Policy Interventions in Tanzania's Dairy Industry, Agrekon, 2016, pp. 81-102. DOI: https://doi.org/10.1080/03031853.2016.1159588

[14] M.K Chernyakov, M.M. Chernyakova, K.Ch. Akberov, Innodiversification model of the digital economy of the agricultural sector, Advances in Social Science, Education and Humanities Research, 2019, 240, $\quad$ DOI: $\quad 10.2991 /$ sicni-18.2019.114. https://www.atlantis-press.com/proceedings/sicni18/55911909

[15] A.S. Belov, A.A. Voronin, M.E. Zhebit, et al. Molochnaya otrasl'-2017: [spravochnik] [Dairy industry-2017 [encyclopedia]]. Moscow, Natsional'nyy soyuz proizvoditeley moloka, 2017, 380 p. (In Rus) http://souzmoloko.ru/netcat_files/498/708/h_87e1aba34 7905e92246823a0c67d66d3

[16] A.S. Belov, A.A. Voronin, M.E. Zhebit, et al. Molochnaya otrasl'-2018-2019: [spravochnik] [Dairy industry-2018-2019 [encyclopedia]]. Moscow, Natsional'nyy soyuz proizvoditeley moloka, 2018, 388 p. (In Rus) https://milknews.ru/klk/otrasl-20182019.pdf

[17] A. Goli, H. Zare, Tavakkoli, R. Moghaddam, A. Sadeghieh, Hybrid artificial intelligence and robust optimization for a multi-objective product portfolio problem Case study: The dairy products, Computers \& industrial engineering, 2019, 137 p., DOI: 10.1016/j.cie.2019.106090

https://apps.webofknowledge.com/full_record.do?produ $\mathrm{ct}=$ WOS\&search_mode $=$ GeneralSearch \&qid=1\&SID= C1qGND7DVdxwZvykwaE\&page $=1 \&$ doc $=15$

[10] Z. Bai, W. Ma, L. Ma, GL. Velthof,

ZB. Wei, P. Havlík, O. Oenema,

MRF. Lee, FS. Zhang, China's livestock transition: Driving forces, impacts, and consequences, Science Advances,2018, pp. eaar8534. DOI:

https://doi.org /10.1126/sciadv.aar8534

[11] Y. Chen, X.Yu, Do subsidies cause a less competitive milk market in China?, Agricultural Economics, 2019, pp.303-314. DOI: https://doi.org/10.1111/agec.12485

[12] O. Ekumankama, A. Ezeoha, C. Uche, The role of multinational corporations in local dairy value chain development: case of Friesland Campina WAMCO (FCW) in Nigeria, International Food and Agribusiness
[18] W. Jacobs; A. M. Souza, R. R Zanini, Combination of Box, Jenkins and MLP/RNA Models for Forecasting, IEEE Latin America Transactions, 2016, 14(4), pp. 1870-1878 https://apps.webofknowledge.com/full_record.do?produ $\mathrm{ct}=$ WOS\&search_mode $=$ GeneralSearch\&qid $=1 \& \mathrm{SID}=$ C1qGND7DVdxwZvykwaE\&page $=2 \&$ doc $=13$

[19] M. K. Chernyakov, M. M. Chernyakova, Digital model of the dairy industry of Siberia, Advances in Economics, Business and Management Research. 2019. - Vol. 105 : International Scientific and Practical Conference on Digital Economy (ISCDE 2019), pp. 284-289. https://www.atlantispress.com/proceedings/iscde-19/125924608 
[20] Chernyakova, M. M. Paradoxical theory of regulation in agriculture (on the example of the dairy industry): monograph, 2019, 160 p. (In Rus) https://www.elibrary.ru/item.asp?id=41342340

[21] M. K. Chernyakov, M. M. Chernyakova, Modeling of process of regulating production, processing and marketing of milk and milk products, IOP Conference Series: Materials Science and Engineering, 2019, 656, Art. 012014 (9 p.). DOI: 10.1088/1757-899X/656/1/012014. 